\title{
Una nota histórica sobre el origen del culto al rey en el antiguo Cercano Oriente
}




\section{Joaquim Azevedo Universidad Peruana Unión}




\section{RESUMEN}

"Una nota histórica sobre el origen del culto al rey en el Antiguo Cercano Oriente" - Una de las incógnitas de la historia universal es el acreditar al rey o monarca características o prerrogativas divinas. Esto es, la deificación de la persona del rey. Las simientes de esta institución religiosa empiezan en forma embrionaria en el periodo de Broce Temprano en el Antiguo Cercano Oriente (ACO) especialmente como fruto de la urbanización. Los tres factores del desarrollo de la religión sumeria más el factor urbano juntamente con la visión del estado tuvieron una gran influencia en este fenómeno de adoración al rey como una deidad.

\section{SUMMARY}

"A Historic Note on the Origin of Worship to the King in ancient Near East" - One of the mysteries of human history is giving divine attributes to the monarch, namely to deify the King. The original form of this institution began in the Early Bronze Age in the Ancient Near Easter, especially as a result of urbanization. The three phases of development of the Sumerian religion plus the urban factor together with the concept of state had a large influence over this religious phenomenon. 


\section{UNA NOTA HISTÓRICA SOBRE EL ORIGEN DEL CULTO AL REY EN EL ANTIGUO CERCANO ORIENTE}

Una de las incógnitas de la historia universal consiste en la acreditación al rey o monarca de características o prerrogativas divinas. Es decir, ¿por qué se produce la deificación de la persona del rey? Los orígenes de esta institución religiosa en su forma embrionaria se remontan al período del Bronce Temprano en el Antiguo Cercano Oriente (ACO) especialmente como fruto de la urbanización. Sin este elemento urbano este fenómeno religioso no ocurriría. Por lo tanto, se hace necesario prestar atención al origen de las ciudades de Sumeria y sus deidades para una mejor comprensión de este fenómeno religioso.

Las primeras civilizaciones nacen en el ACO con el desarrollo de pequeñas villas y ciudades aledañas a las fuentes de agua potable, como por ejemplo el río Éufrates, el Tigris, el Jordán y el Nilo. Sin embargo, las civilizaciones colindantes al Éufrates, especialmente en el sureste, son las que recibirán atención en este estudio.

El ACO ha sido considerado la cuna de la civilización. Esta aseveración tiene todo el apoyo de la arqueología. Es aquí, en esta región del mundo, donde se encuentra el poder político unido o fundido con 
el religioso por primera vez en términos de cómo se entiende la palabra "civilización". ${ }^{1}$ Este fenómeno, el culto al monarca, podía existir de manera concomitante en otros lugares como, por ejemplo, en Egipto. Sin embargo, es al final del tercer milenio antes de Cristo, que encontramos, en el Fértil Creciente, este modelo de gobierno que a su vez servirá de parámetro a las civilizaciones posteriores. ${ }^{2}$ Ahora bien, su origen, sea por la conveniencia política del monarca o el interés religioso de los sacerdotes, es todavía un enigma de la historia.

\section{Las ciudades estado de Sumeria}

Es en el origen de la civilización urbana donde encontramos más claramente esta asociación de lo divino con lo humano en la persona del rey. En el relato bíblico se puede ver una indirecta insatisfacción de Dios con la construcción de ciudades en el comienzo de las civilizaciones. En estos inicios, aparentemente, quienes construían ciudades eran rebeldes a Dios; por lo tanto construir centros urbanos era, según el relato bíblico, un

${ }^{1}$ Para un estudio sobre las civilizaciones de Mesopotamia véase Martinus Adrianus Beek, Atlas of Mesopotamia: A Survey of the History and Civilizations of Mesopotamia from the Stone Age to the Fall of Babylon, trad., por D. R. Welsh (New York, NY: Nelson, 1962); J. B. Pritchard, ed., Ancient Near Eastern Text, 3ra. ed. (Princenton: Princenton University Press, 1969). Samuel Noah Kramer, The Sumerians: Their History, Culture, and Character (Chicago: University of Chicago Press, 1964); P. Garelli, "El nacimiento de la civilización urbana," "Sumer", y "Los siglos oscuros", en El próximo oriente asiático desde los orígenes hasta las invasiones de los pueblos del mar (Barcelona: Ediciones Surco, 1970), 11-29; 31-46; 99-119.

${ }^{2}$ Por ejemplo Babilonia o Roma. 
acto de rebeldía. Dios, Jehová, no era un dios local o de una ciudad como los dioses del ACO, tal como se ve en los siguientes textos:

Génesis 4:17 - Caín edificó una ciudad a la cual llamó según el nombre de su hijo Enoc.

Génesis 10:9-12 - 'Él fue un vigoroso cazador delante de Jehová, por lo cual se suele decir: "Como Nimrod, el vigoroso cazador delante de Jehová". ${ }^{10} \mathrm{Al}$ principio, su reino abarcaba Babel, Erec, Acad y Calne, en la tierra de Sinar. ${ }^{11}$ De aquella tierra salió para Asiria y edificó Nínive, ciudad Rehobot, Calah ${ }^{12}$ y Resén, entre Nínive y Calah. Ésta es una gran ciudad.

Génesis 11:4-9 - ${ }^{4} Y$ dijeron: "Venid, edifiquémonos una ciudad y una torre cuya cúspide llegue al cielo. Hagámonos un nombre, no sea que nos dispersemos sobre la faz de toda la tierra". "5ehová descendió para ver la ciudad y la torre que edificaban los hombres. ${ }^{6}$ Entonces dijo Jehová: "He aquí que este pueblo está unido, y todos hablan el mismo idioma. Esto es lo que han comenzado a hacer, y ahora nada les impedirá hacer lo que se proponen. ${ }^{7}$ Vamos, pues, descendamos y confundamos allí su lenguaje, para que nadie entienda lo que dice su compañero". ${ }^{8}$ Así los dispersó Jehová de allí sobre la faz de toda la tierra, y dejaron de edificar la ciudad. ${ }^{9}$ Por tanto, el nombre de dicha ciudad fue Babel, porque Jehová confundió allí el lenguaje de toda la tierra, y desde allí los dispersó sobre la faz de toda la tierra.

A pesar de esta aparente desaprobación divina expresada en el relato bíblico, en Sumeria, debido a la revolución urbana del Bronce Temprano, ${ }^{3}$ junto con la

${ }^{3}$ Para una mejor comprensión del fenómeno de las ciudades estado del período del Bronce véase W. R. Halliday, The Growth of the City State: Lectures on Greek and Roman History (Chicago, IL: Argonaut, 1967); Jonathan Haas, The Evolution of the Prehistoric State (New York, NY: 
explosión demográfica, la acumulación de bienes, la necesidad de protección contra las invasiones arameas, la necesidad de fortificaciones y de un ejército formalizado, se desarrolla un cambio que va de la organización tribal parcialmente nómade hacia una urbana. En este proceso el jefe tribal pasa a ser un rey electo por el pueblo de un grupo social ya sedentario. En otras palabras, se trata de una democracia embrionaria en el contexto de una ciudad estado.

Estos grupos sociales se transforman en ciudades amuralladas, en el caso de los sumerios, que constituían una suerte de feudo. Cada ciudad estaba rodeada por una franja de tierras fértiles aledañas a una fuente de agua potable y que servía de irrigación. Esta ciudad era fortificada por murallas de piedras o ladrillos de barro cocidos al fuego, protegidas por el ejército organizado por el rey siendo apoyado por el pueblo. Dentro había un templo erigido al dios regional de la época considerados como nómades, pero ahora practicando un ritual elaborado y sofisticado. Este dios era el patrón del distrito y el rey era el "pastor" de su pueblo y benefactor del templo. Se desarrolló una casta sacerdotal, gracias al templo, mantenida inicialmente por las ofrendas del pueblo; posteriormente esta función pasó a los monarcas que eran legítimamente coronados como descendientes de los dioses y, por lo tanto, se constituían en protectores

Columbia University Press, 1982); Maurice Godelier, "Infraestructure, Societies, and History," Current Anthropology 19 (1978) 763-771; Andre Gunder Frank, "Bronze Age World System Cycles", Current Anthropology 34 (1993) 383-430; Norman Yoffee, "The Decliene and Rise of Mesopotamian Civilization: An Ethnoarchaeological Perspective on the Evolution of Social Complexity", American Antiquity 44 (1979) 5-35. 
de los intereses del templo. ${ }^{4}$ El interés en la posesión de la tierra y sus riquezas era común al rey y al clero. Los sacerdotes representaban las aspiraciones religiosas y políticas del pueblo. No debemos olvidar que los sacerdotes eran la conciencia moral y espiritual del grupo social que representaban.

En el Período Dinástico Temprano I encontramos la existencia de una forma de gobierno democrático, aunque todavía en forma arcaica. Aquí el monarca era escogido de por vida debido a la capacidad que ya había demostrado a lo largo de su vida, sea ésta militar, económica o administrativa. Cada atributo, dependiendo de las circunstancias, lo haría un perfecto candidato al liderazgo. La ciudad central era Nippur y ésta era considerada como el centro religioso deSumeria, y siempre lo sería hasta el fin de la civilización sumeria al final del tercer milenio antes de Cristo.

La ciudad, como centro urbano, se originó como consecuencia de las necesidades del templo. Existía una necesidad de trabajadores brazales en el campo, artesanos, artífices, constructores, cocineros, fabricantes de tejidos y ropas, albañiles, panaderos, vaqueros, fabricantes de utensilios domésticos y herramientas de trabajo en bronce, vendedores, almaceneros, transportadores en caravanas, etc., todos asalariados por el templo. Se formaba así alrededor del templo un vecindario con estos

${ }^{4}$ William W. Hallo y William K. Simpson, The Ancient Near East: a History (Orlando, FL: Harcourt Brace Jovanovich College Publisher, 1971), 33; para una comprensión del tema véase A. Leo Oppenheim, "Mesopotamia: Land of Many Cities", en Ira M. Lapidus, ed., Middle Eastern Cities: A Symposium on Ancient, Islamic, and Contemporary Middle Eastern Urbanism (Los Angeles: University of California Press, 1969), 3-18. 
trabajadores y sus familias. Antes eran nómades pero debido a estas necesidades del templo se asientan en un territorio permanente. $\mathrm{Al}$ crecer se necesitaba de un líder político que mantenga las leyes, el orden y un ejército organizado. De esta manera se daba origen a una ciudad. Con el pasar del tiempo el rey asumió parte de estas funciones de dar empleo y satisfacer la necesidad del templo como también de las personas. Paulatinamente las ciudades y el rey pasaron a estar estrictamente relacionados con la deidad. Por lo tanto, la aparición de la ciudad contribuyó a posibilitar la adoración al pontífice máximo que la gobernaba, es decir, al rey. ${ }^{5}$

\section{Factores que contribuyeron al desarrollo del culto al rey}

Como ya fue mencionado, las ciudades fueron uno de los principales factores que contribuyeron en el surgimiento de la adoración al monarca. Las ciudades de Sumeria experimentaron un crecimiento demográfico explosivo en el Período Dinástico II causando varios problemas, como la necesidad de tierras fértiles para la producción de alimentos y dominio sobre las fuentes de agua potable. En muchos casos, las guerras eran la solución. Estas necesidades estaban relacionadas con las dádivas de los dioses regionales; en consecuencia

${ }^{5}$ Bruce G. Trigger, "Inequality and Communication in Early Civilization", en B.G. Trigger, ed., Time and Tradition: Essays in Archaeological Interpretation (New York, NY: Columbia University Press, 1978), 202, citado por Deborah L. Nichols y Thomas H. Charlton, eds., The Archaeology of City States: Cross Cultural Approaches (Washington, DC: Smithsonian Institution Press, 1998), 13. 
las guerras tenían un tono sagrado y el vencedor era el que los dioses o el dios había reconocido como benefactor legítimo de los templos de los dioses y el perdedor lógicamente como el que había pecado contra la divinidad, fuese ésta local o de Nippur.

Cada ciudad tenía un dios patrono o una diosa, matrona. Por lo tanto, el rey pasa de ser elegido por el pueblo a escogido por los dioses. La casta sacerdotal crece grandemente en número, ya que los reyes necesitan su apoyo político para dominar la conciencia de su propio pueblo por medio de los mitos y creencias propagadas por los sacerdotes con respecto al propio rey y su supuesta descendencia divina. De esta manera los templos ya no son mantenidos solamente por las ofrendas de los oferentes, sino principalmente por la tesorería del rey.

Según Postgate tres elementos pueden ser reconocidos en el gobierno de un rey indicando que él tomaba las prerrogativas de un dios. Éstos son los siguientes: (a) su nombre venía precedido por la señal cuneiforme que representaba una deidad; (b) los adornos de su cabeza tenían cuernos, lo que era típico en la iconografía para indicar a un dios, y(c) la construcción de un templo para su veneración y adoración. ${ }^{6}$ Por lo tanto, se presenta a continuación un breve análisis de la religión sumeria como otro factor importante en el desarrollo de este fenómeno.

${ }^{6} \mathrm{~J}$. N. Postgate, Early Mesopotamia: Society and Economy at the Dawn of History (London: Routledge, 1992), 266. 


\section{La religión sumeria}

La religión sumeria era del tipo monista. Esto significa que los dioses estaban involucrados en todas las actividades de vida de los ciudadanos de Sumeria. Los dioses participaban de la misma clase de problemas y frustraciones que tenían los seres humanos. ${ }^{7}$ Todos podían tener la complacencia de los dioses si practicaban bien los rituales prescritos para un determinado dios, como si fuera una fórmula mágica. Hay elementos de la religión sumeria que son muy característicos de este monismo: (a) los dioses poseen atributos humanos; (b) estos estaban en íntima relación con la naturaleza; (c) los sumerios veían en la sociedad de los dioses algo similar a la sociedad de los seres humanos. Ambas sociedades se interrelacionaban. ${ }^{8}$

La semejanza entre los dioses y los seres humanos era muy fuerte. Todos los dioses del panteón habían sido creados, por lo tanto, no eran eternos. Solamente Apsu tendría algo de eternidad. Esta comunidad de dioses necesitaba de organización y ésta toma la forma de un estado político. En esta cosmovisión nada estaba destinado a durar eternamente, por lo tanto, podían venir cambios repentinamente. Los ciudadanos debían siempre procurar los favores de los dioses sin saber el resultado, es decir, sin saber si éste sería positivo o duradero. Tenían que mantener a los dioses complacidos. Ya que el cosmos era visto como

7J. I. Packer, et al., "Religiones y culturas paganas", en El mundo del Antiguo Testamento (Miami, FL: Vida, 1985), 102-119.

${ }^{8}$ E. A. Speiser, "Ancient Mesopotamia”, en Robert C. Dentan, ed., The Idea of History in the Ancient Near East (New Haven: American Oriental Society, 1983), 43. 
un estado gobernado por los dioses o la asamblea de los mismos; el estado terrestre debía también corresponder con el estado cósmico. En la mitología de Mesopotamia los dioses otorgaban inmortalidad a aquellos que ellos querían. Por ejemplo a Ut-napishtin, el Noé de la mitología sumeria, los dioses le dan la eternidad.

Por lo tanto, los reyes eran vistos como receptores directos de las bendiciones de los dioses locales $\mathrm{y}$, tal vez, como la conexión más próxima que los ciudadanos tendrían con los dioses. Los reyes eran, en principio, una especie de mediadores entre el pueblo y la deidad. Esto se puede observar en el desarrollar de la historia sumeria. Los sumerios creían que el reinado/estado había sido bajado del cielo después del diluvio. Tres símbolos representaban el reinado: una corona, un cetro y un trono. En la iconografía de los sellos se pueden ver estos tres elementos como dádivas del dios al rey. En el himno a Rim-sin rey de Larsa se dice:

En Larsa donde el reinado se ha establecido, tú has sido escogido para pastorear Sumeria y Akkad.

Que An coloque la corona sagrada en tu cabeza,

Que él te establezca grandemente sobre el trono de la vida,

Que él llene tus manos con el cetro de la justicia,

Que él amarre en tu cuerpo el cetro que controla los pueblos,

Que te haga tomar el cetro, que multiplique los pueblos, Que abra el seno brillante del cielo y que las lluvias del cielo caigan sobre ti. ${ }^{9}$

${ }^{9}$ Charpin D., Le Clergé d'Ur au Siècle d'Hammurabi (XIXe-XVIIIe siècle av. J.C.), (Geneva: 1986a), 275-6, en Postgate, Early Mesopotamia: Society and Economy at the Dawn of History, 261 


\section{Tres fases del desarrollo de la religión sumeria}

En la primera fase de la religión sumeria se veían las fuerzas de la naturaleza como poderes sobrenaturales, que dominaban el mundo en el que vivían. Estos poderes podían dar vida o destruirla por medio de diluvios, tempestades o sequías. Estos poderes eran identificados como Apsu. Esta creencia tenía su fundamento en las características de la misma región en la que los sumerios vivían. Sumeria se encontraba justamente en una región privilegiada por las aguas del río Tigris y Éufrates. Estos ríos tenían muchos afluentes, lagunas y pantanos que eran la causa visible de toda la vida de Sumeria.

Los habitantes de esta región observaban que los animales, tales como jabalíes, peces, pájaros, patos, gacelas y otros, existían gracias a estos ríos. Así deducían que las aguas los habían criado. Las plantas eran abundantes, pero al ir hacia el sur o el norte encontraban el desierto o las montañas donde no había agua y, por lo tanto tampoco había vida abundante. Lógicamente, en la cosmovisión sumeria, el agua era la fuente misteriosa de la vida. Su cosmovisión podría resumirse en el dicho "sin agua no hay vida". En la Mesopotamia, sus habitantes encontraban agua cuando cavaban el suelo, lo que los llevó a pensar que había un mar de agua potable debajo de la tierra llamado Apsu. Éste era la fuerza misteriosa de la vida. ${ }^{10}$

${ }^{10}$ Es interesante observar que las civilizaciones que llegaron a tener un desarrollo religioso similar al de los sumerios tuvieron semejantes fases en su religión. Un ejemplo sería el de las ruinas de Pachacamac en Lima, Perú. Se trata de las ruinas de un templo dedicado a un oráculo llamado 
Este concepto resultó útil mientras la vida era simple y pastoril, con tribus que vivían en aldeas o eran nómades. Veían en Apsu la fuente de la fuerza del bien y del mal. La misma lluvia que regaba las plantas, también tenía el poder de destruir las plantas y los seres humanos con diluvios y tempestades o por falta de agua. Por lo tanto, debían aprender a dominar esta fuerza por medio de rituales místicos basados en las fuerzas de la naturaleza y en las estaciones del año.

Con el crecimiento de la población y la formación de ciudades el concepto de Apsu se volvió inadecuado. Con una población urbana se necesitaba una representación más visible de la deidad que mantenga la unidad político-religiosa de la población. Así se produce la segunda fase del desarrollo religioso en el ACO. Se trata del concepto teriomórfico de los dioses. En vez de ser considerados como una fuerza misteriosa, como el Apsu, los dioses reciben una representación visible en forma de un animal (terion), o parte del mismo. Así, Apsu pasa a ser visto como un ave gigantesca, tal vez un fénix, que con las alas cubre el sol y causa las tempestades y lluvias y después se esconde en los lagos o

Pachacamac. Éste inicialmente era un oráculo que ayudaba en la producción de alimentos, especialmente el maíz. Con el tiempo esta fuerza pasa por una transformación y es representada en forma humana, pero en el símbolo del dios antropomórfico todavía se pueden percibir las representaciones de las formas teriomórficas. La figura es similar a un tótem: arriba se encuentra el dios en forma antropomórfica y abajo aparecen figuras con cabezas de aves, seguidas por figuras con cabezas de felinos y luego de víboras. Esto representaba las fuerzas misteriosas del aire, de la tierra y las de debajo de la tierra. Este dios era y es todavía adorado; las ruinas cubren un total de 500 hectáreas con 16 pirámides escalonadas de diferentes épocas muy semejantes a la de Ur. Estas civilizaciones también adoraban al emperador como un descendiente del dios supremo. 
pantanos dejando que se vean solamente sus antenas en forma de cañizos de plantas. Se puede percibir este nuevo concepto en la asociación de Ishtar con un león, de Marduk con un dragón o buey, y del dios de la agricultura con plantas creciendo en su cabeza. En esta fase empezaron a surgir templos para dirigir los rituales de estos dioses, con el fin de obtener buenas respuestas de los mismos.

En la tercera fase del desarrollo religioso, se presenta el antropomorfismo. Los dioses son claramente asociados con cualidades físicas y morales puramente humanas. Los dioses deben ser criados, tienen la forma física de seres humanos, mueren, se casan, adulteran, matan, sufren, tienen sangre, etc. En esta fase los dioses son representados en figuras talladas, estatuas, sellos, en piedra, madera, siempre en forma humana. ${ }^{11}$

Teniendo en consideración estas tres fases de desarrollo se puede concluir que en esta cosmovisión la adoración del monarca resultaría más fácilmente aceptable. Había muchas semejanzas entre los dioses y los monarcas. Ambos eran poderosos, fueron creados por dioses superiores, tenían el poder de dar la vida o la muerte a sus servidores y al pueblo, protegían o destruían, ambos tenían funciones en los templos y eran mortales. Ambos establecían leyes para guiar a su pueblo. Ambos fueron criados para gobernar. La mitología apoyaba la idea de que el rey era de origen divino. Ambos debían ser complacidos, tenían el

${ }^{11}$ H. W. F. Saggs, People of the Past: Babylonians (Norman, OK: University of Oklahoma Press, 1995), 34-36. 
poder de producir el bien y el mal y eran adorados por rituales semejantes.

\section{Coronación del rey sumerio}

Se puede observar que la coronación tomaba lugar en el templo del dios con el cual el rey estaba relacionado. El éxito de su reinado y la prosperidad del reino dependían de en qué medida el rey complacía a los dioses. El rey, muy a menudo, tomaba para sí el crédito de la prosperidad económica del reino, y el crédito por las victorias en las guerras era debidamente dado a los dioses que, por medio del rey, obtuvieron el triunfo.

En su coronación el rey ofrecía ofrendas al templo y el hecho de que el sacerdote recibiera éstas significaba que el rey había sido aceptado como tal por la deidad. Se sentaba en un trono cubierto de lana de oveja, pues sería el pastor designado por su dios para cuidar de su rebaño, y recibiría un cetro y una corona (véase el himno a Rim-sin ya mencionado). Después de ser coronado, el rey sería responsable por gran parte de la prosperidad del reino juntamente con la deidad de la región que gobernaba y que lo coronó. Así se legitimaba su gobierno delante de la población. Esto se puede ilustrar con el relato de la coronación del rey de Uruk:

Él penetra al recinto de Enanna.

Él se acercó a la plataforma del trono resplandeciente.

Él colocó el cetro en su mano.

Él se acercó a la plataforma del trono de Nin-men-na

("Señora de la corona").

Él ajusta la corona de oro en su cabeza.

Él se acerca a la plataforma del trono de Nin-Pa ("Señora del cetro"). 
Después que ella desechó su nombre "de pequeñez", ella no llamó su nombre.

Pero lo llamó "nombre del reinado". ${ }^{2}$

\section{La visión del Estado en esta cosmovisión}

Para entender cómo un rey llegaba a ser adorado como un dios debemos comprender que el estado terrestre era concebido como una copia del celestial y se asumía que el dios, sea este local o nacional, escogía al rey como su pastor para pastorear a su pueblo concediéndole autoridad y poder. Esta delegación de poder era común incluso entre los dioses. Note que Hammurabi escribe, en el prólogo de sus leyes, que Enlil otorga a Marduk la supremacía sobre todos los dioses de Sumeria y que Anum y Enlil llamaron a Hammurabi para mejorar las condiciones de vida del pueblo de Mesopotamia. Así vemos tres entidades jerárquicas en asamblea para gobernar el reino, Enlil, Marduk y el rey, en este caso Hammurabi. ${ }^{13}$

Los tres factores del desarrollo de la religión sumeria más el factor urbano juntamente con la visión del estado ejercieron una gran influencia en la aparición del fenómeno de la adoración al rey como una deidad. A continuación se presentará una breve historia de los reyes que tomaron sobre si las prerrogativas divinas en Sumeria. La misma servirá para ejemplificar el

${ }^{12}$ H. A. Frankfort, Kingship and the Gods. A Study on Ancient Near Eastern Religion as the Integration of Society and Nature (Chicago, IL: University of Chicago Press, 1948), 245-246, citado en Postgate, 263.

${ }^{13}$ Postgate, 268. 
origen de este fenómeno religioso, pero no pretende ser comprehensiva, sino sólo ilustrativa.

\section{Breve historia de los reyes que tomaron sobre sí las características divinas: desde Emmerkar hasta Hammurabi}

Unos de los primeros reyes sumerios en reconocer los resultados políticos de beneficiar el templo del dios local fue Emmerkar. Él percibió que si conseguía el apoyo de la casta sacerdotal tendría la lealtad de los moradores de la región donde pretendía gobernar, pues los sacerdotes eran la voz del dios de Nippur y de la deidad regional. De esta manera, el gobierno de Emmerkar ${ }^{14}$ recibiría la legitimidad necesaria ante de los ojos de la población, a través de las declaraciones de los sacerdotes expresadas en forma de himnos, mitos o folclore al respecto. Este rey recibió beneficios del templo, se compuso un himno ${ }^{15}$ en honor de su persona y además recibió el título de "hijo del dios sol". Al mismo tiempo o algo después encontramos a Lugal-banda rey de Uruk. ${ }^{16}$ Es representado en el arte sagrado en piedras, vestido de dios o como dios junto con los dioses.

${ }^{14}$ Según Halo, Gilgamesh podría haber sido pariente de Emmerkar. La epopeya de Gilgamesh mencionada en fuentes posteriores consideraba a Gilgamesh como hijo de Lugal-banda y su esposa divina Nansun y nieto de Emmerkar. Halo, 45.

${ }^{15}$ En cuanto a los poemas de Emmerkar véase Adele Berlin, Emmerkar and Ensuhkeshdanna. A Sumerian Narrative Poem, en Occasional Publications of the Babylonian Fund, 2 (Philadelphia: The University Museum, 1976).

${ }^{16} \mathrm{El}$ nombre de este rey es precedido por la palabra dios en la lista sumeria de los reyes, "el dios Lugal-banda ...", ANET, 266. 
Gilgamesh, hijo de Lugal-banda, ${ }^{17}$ se consideraba $1 / 3$ hombre y $2 / 3$ dios. $^{18}$ Su madre fue la sacerdotisa Ninsum. Por otro lado, el rey Eemeragesi de Kish fue el primero que construyó el templo de Enlil en la ciudad de Nippur, empezando así una larga tradición, que colocó a esta ciudad como el centro religioso de Sumeria, donde todos los monarcas subsiguientes de Sumeria debían venir a buscar su legitimación como reyes, beneficiando al templo y manteniendo a los sacerdotes del mismo. De esta manera el reinado estaba ahora involucrado con la religión para no separarse nunca más, a excepción de cortos períodos de tiempo, como ocurrió durante la invasión de los gutianos. Éstos provocaron un estado caótico en Sumeria donde la veneración de los monarcas fue abandonada por cerca de cincuenta años. El rey estaba tornándose en los brazos de acción de la divinidad, la casta sacerdotal ya era la voz de dios y los ciudadanos libres los servidores y favorecidos del/los dios/es y del templo.

El Período Dinástico Temprano III introduce en el ACO una innovación. Ésta consistió en la total extinción de la práctica de que el rey sea elegido por el pueblo, la cual fue reemplazada por la elección del mismo por determinación de los dioses o del dios local. Esta innovación se volvió la fórmula única para que las dinastías funcionasen perfectamente; implicaba que un rey tenía el derecho divino de reinar en un determinado territorio y este derecho era heredado o transferido a sus hijos, tuviesen éstos o no el talento para gobernar.

\footnotetext{
${ }^{17}$ ANET, 49.

${ }^{18}$ ANET, 73.
} 
Los que legitimaban este derecho eran los sacerdotes, especialmente de Nippur, en sociedad con los de la ciudad a ser gobernada.

El sistema dinástico, establecido durante este período, perduró durante los siguientes siglos, incluso después que los sumerios desaparecieron. Los reyes empezaron a hacer uso de este derecho para afirmar la legitimidad de sus gobiernos. Sus hijos e hijas eran designados como sacerdotes o sacerdotisas de los dioses que habían concedido la legitimidad al rey-padre. En general la hija de un rey iba para el templo de Nippur y el hijo para el templo local de la ciudad gobernada por el rey-padre. Ya existía aquí la tradición o creencia de que el príncipe escogido para continuar el linaje del padre era de descendencia divina. El rey-padre tenía que cohabitar con la sacerdotisa de su dios, en un casamiento sagrado, y el hijo que nacía pasaba a ser el futuro rey; éste a su vez se consideraba una parte dios y una parte hombre como lo había hecho Gilgamesh. ${ }^{19}$ Por consiguiente el rey podía garantizar todavía más su autoridad de gobierno y el orden del cosmos.

El rey de Lagash, Urukagina fue conquistado por Lugal-zagesi de Umma/Uruk. Este rey benefició al templo de Nippur con nuevas construcciones y mantuvo a los sacerdotes con alimentos y ofrendas de animales y metales preciosos. Con esta táctica alcanzó la hegemonía de toda Sumeria y Akkad. Sus victorias fueron descritas en los anales del templo de Nippur. Su reino fue apoyado por los sacerdotes y los dioses de Sumeria; este

${ }^{19}$ Civil M., "Reading Gilgamesh", Aula Orientalis 17-18 (1999-2000) 179-189. 
reino se extendía desde el lago salado (Golfo Pérsico) hasta el mar grande (Mediterráneo), convirtiéndose así en el primer sacro imperio sumerio donde habitaban los dioses de Sumeria. Acerca de los dioses habitando en Sumeria se puede leer en la literatura de la época en relación a la creación y el diluvio. ${ }^{20}$

Cuando Sargón ${ }^{21}$ conquista a Lugal-zagesi de Uruk, juntamente con 50 de sus gobernantes, establece una base nueva para la cultura de Mesopotamia. Su período de gobierno es considerado como una explosión cultural en toda Sumeria y Akkad. Su nombre era Sharru-Ken-u, "el rey es legítimo". Este nombre podría deberse a su nacimiento humilde. Su madre era una sacerdotisa que tuvo una relación ilícita y al nacer el niño ella lo puso en un cesto y lo colocó en el Éufrates. Allí el pequeño Sargón fue encontrado por un jardinero que lo educó como tal. ${ }^{22} \mathrm{El}$ joven tenía una preferencia por la diosa Ishtar. Posteriormente se tornó copero del rey Ur-Zababa de Kish. Sargón ${ }^{23}$ consiguió, con el tiempo, llegar a ser el rey que reinó por 55 años en la ciudad que fundó, llamada Acad, a las márgenes del río Éufrates. Sargón logró unir todo el creciente fértil desde Ur hasta Purushkhanda en el sur de Asia Menor y desde Elam hasta las tierras de los amorreos al oeste. Fue un gran benefactor de los templos de Nippur, Ur y Uruk.

${ }^{20}$ ANET, 37-59.

${ }^{21}$ Hallo y Simpson, 54-60; Veronika Afanas'eva, “Das sumerische Sargon-Epos. Versuch einer Interpretation", Altorientalische Forschungen 14 (1987) 237-246.

\footnotetext{
${ }^{22}$ ANET, 119.

${ }^{23}$ ANET, 266-268.
} 
La era sargónida estaba destinada a ser el modelo de otras grandes civilizaciones posteriores.

Los hijos mellizos de Sargón, Man-ishtu-Shu, "quien es como él", y su hermano reinaron en Aššur y Susa, respectivamente. Esto está atestiguado en documentos de la época. Man-ishtu-Shu construyó el templo a Ishtar en Nínive. Ambos fueron muertos por sus siervos con sus propios cetros que incluían los cilindrossellos que representaban el reino. Después de la muerte de estos dos hermanos, Naram-Sin el hijo de Man-ishtushu reinó por 56 años. Ésta fue la época más brillante del período sargónico. Es interesante reconocer los títulos que este rey recibió aun en vida. Uno de los primeros es "señor/sumo sacerdote de Sumeria"; los otros son "rey de las naciones", "señor/sumo sacerdote de Uruk", "rey de Akkad", y "rey del territorio de Uruk". Después de la mitad de su reinado introdujo un nuevo título: "el rey de los cuatro cantos de la tierra". No contento con los honores terrestres tomó el título de "dios de Akkad". Este nuevo título se desarrolló rápidamente en un culto al rey vivo y a sus fallecidos predecesores. No había distinción entre este culto y el de los dioses; hasta templos y estatuas fueron construidos en honor a su persona. Uno de los últimos títulos que toma Naram-Sin fue "el grande". Este último fue pasado a las siguientes generaciones. Su hija fue la sacerdotisa del dios de la Luna de Ur. Naram-Sim encontró posiciones políticas para toda su familia. ${ }^{24}$

Después de Naram-Sin su hijo Shar-Kali-Sharri reinó por 25 años y su imperio vino a caer debido a varios

${ }^{24}$ Hallo y Simpson, 60-61. 
motivos: (a) la invasión de los gutianos, (b) ataques de los amorreos, (c) la invasión de los Lullubi del noreste, y (d) los elamitas. En ese período las ciudades de Sumeria volvieron a la condición de ciudades estados. Cada una adquirió independencia como un estado feudal, como lo habían sido antes. Sin embargo, después de casi 50 años de anarquía social, una ciudad se empezó a destacar: Lagash, con su rey llamado Gudea. Así, de las cenizas del imperio sargónico, surgió nuevamente la civilización sumeria.

Con la invasión de tribus nómades Sumeria recibió la influencia de diferentes culturas y religiones. Esta influencia amenazó la existencia de la religión sumeria, especialmente la práctica de adorar al monarca. Pero, como generalmente ha ocurrido en la historia humana, no es el más fuerte el que gana, sino la cultura que más cautiva la imaginación de los seres humanos. Así como Roma gana la guerra contra los griegos, pero estos últimos ganan a los romanos para su filosofía, así también pasó en el ACO. Los sumerios fueron invadidos pero los invasores no deseaban destruir la civilización sumeria; sólo querían ser sumerios y disfrutar de los beneficios de esa cultura. El resultado fue una amalgama cultural que atrasó el desarrollo del culto al monarca por un corto tiempo.

Los gutianos no eran una fuerza organizada ni tampoco una civilización capaz de gobernar ciudades y un vasto territorio. Eran nómades que vivían todavía en tribus y clanes que a veces luchaban entre ellos mismos. ${ }^{25}$

${ }^{25}$ Para obtener más información sobre los gutianos véase D. Frayne, “Old Babylonian Period (2003-1595 BC)", en The Royal Inscriptions of Mesopotamia. Early Periods, vol. 4 (Toronto/Buffalo/London: University 
Esta debilidad hizo que muy pronto los sumerios se reorganizasen y los conquistasen. El rey que obtuvo este logro fue Utu-hegal de Uruk. ${ }^{26}$ Reinó por siete años y venció a las fuerzas de los gutianos, pero no los expulsó completamente, pues estos últimos ya estaban establecidos y no eran una amenaza para su reino; Utuhegal solamente retomó el poder nuevamente para los sumerios.

Cuando Utu-hegal muere, su hijo, Ur-nammu subió al trono. Este reconstruye el templo de Uruk para Innana ${ }^{27}$ y el templo de Nanna de Ur. El enorme ziggurat de Ur que aun hoy se puede apreciar, fue obra de su gobierno. Lo más importante fue su apoyo a los sacerdotes de Nippur y del templo del dios Enlil, el principal dios de Sumeria. ${ }^{28}$ Estos logros lo colocaron en una posición de autoridad e importancia, no solamente en relación con la población sino también con el clero de Nippur. En cuatro años este rey fue coronado como monarca de toda Sumeria y Akkad. El acontecimiento fue conmemorado con un himno especial dedicado a su persona. Su hija fue establecida como sacerdotisa

of Toronto Press, 1990); idem, "Sargonic and Gutian Periods (2334-2113 BC)" en The Royal Inscriptions of Mesopotamia. Early Periods, vol. 2 (Toronto/ Buffalo/London: University of Toronto Press, 1993).

${ }^{26} \mathrm{~F}$. Thureau-Dangin, "Un double de l'inscription d'Utu-hegal", Revue d'Assyriologie 10 (1913) 98-100.

${ }^{27}$ Diane Wolkstein y S.N. Kramer, Innana Queen of Heaven and Earth: Her Stories and Hymns from Sumer (New York, NY: Harper and Row, 1983).

${ }^{28}$ Con respecto a la religiosidad de Ur- Nammu, véase G. Castellino. "Urnammu. Three Religious Texts", Zeitschrift für Assyriologie 52 (1957) 1-57. Idem, "Urnammu. Three Religious Texts (continued)", Zeitschrift für Assyriologie 53 (1959) 106-132. 
del templo de Ur y su hijo del de Uruk. Los templos y el clero eran sostenidos con alimentos, impuestos y protección del monarca.

Las ciudades estados se unieron con Ur-nammu en una alianza a cambio de protección contra posibles tribus nómades, como los amorreos. El logro más conocido de este monarca fue su código de leyes. Éste sirvió de modelo a los reyes que lo siguieron, incluso siglos después, al establecer leyes similares. Estas leyes son conocidas como leyes casuísticas, pues plantean una condición para un caso y la punición: "si un hombre hiciera ..., él tendrá que pagar ...". Ur-nammu recibió el título de "pastor de su pueblo". Por una ironía de la vida Ur-nammu, el rey pacífico, murió en batalla, ${ }^{29}$ algo muy raro en esa época. Su gobierno favoreció la adoración del monarca, aunque Ur-nammu no lo había planeado. Debido a sus leyes fue considerado no solamente como el protector de su pueblo, sino también como el pastor. Éstos son atributos y prerrogativas encontrados en los dioses sumerios.

Shulgi hijo de Ur-nammu tomó su lugar. Reinó por 48 años. La primera mitad de su reino fue de paz y prosperidad. La segunda mitad fue de guerra y estabilidad comercial. Las guerras eran contra las tribus invasoras que codiciaban los beneficios de la cultura sumeria. Este monarca continuó la importación de

${ }^{29}$ Samuel Noah Kramer, "The Death of Ur-Nammu", 193-214 en Mori, Masao, Ogawa, Hideo y Yoshikawa, Mamoru, eds. Near Eastern Studies. Dedicated to H. I. H. Prince Takahito Mikasa on the Occasion of His Seventy-Fifth Birthday (Wiesbaden: Otto Harrassowitz, 1991) ; idem, "The Death of Ur-Nammu and His descent to the Netherworld", Journal of Cuneiform Studies 21 (1967) 104-122. 
lapislázuli y estaño del este, de Elam. La agricultura continuó su alta producción y el exceso era usado para el intercambio comercial. Mesopotamia, la tierra de los dioses sumerios, producía muchos granos, lana, pescados secos, cuero, bronce y dátiles. Las deudas pasaron a pagarse con plata. ${ }^{30} \mathrm{El}$ uso de este mineral fue tan grande que recibió tres funciones comerciales a partir de Shulgi que continuarían en la historia de la humanidad: (a) capital de cambio internacional, (b) unidad contable, y (c) valor básico padrón. Shulgi estableció un calendario rotativo en el cual cada ciudad se obligaba a contribuir con los gastos del estado y de los templos.

Después de más de cien años sin la adoración del monarca este culto, que había sido abandonado o dejado sin apoyo desde los tiempos de Naram-sin por causa de la invasión de los gutianos, es ahora instituido nuevamente con gran fuerza y vitalidad por Shulgi. Se componen himnos en su honor ${ }^{31}$ y se construyen templos para rendirle culto. El mismo, para dar legitimidad a su gobierno, se llamó hijo de Lugal-banda y hermano de Gilgamesh. Shulgi estableció una escuela de escribas en Nippur y se consideraba un entendido en todas las ciencias del currículo de Nippur. Sus dos hijos, Aamar$\sin$ y Shu-sin, ${ }^{32}$ le sucedieron. El primero murió de una

${ }^{30} \mathrm{P}$. R. S. Moorey, Ancient Mesopotamian Materials and Industry: The Archeological Evidencia (Winona Lake, ID: Eisenbrauns, 1999), 237.

${ }^{31}$ Jacob Klein, "A Self-laudatory Shulgi Hymn Fragment from Nippur", en Cohen, Mark E., Snell, Daniel C. y Weisberg, David B., eds., The Tablet and the Scroll: Near Eastern Studies in Honor of William W. Hallo, (Bethesda, Md: CDL Press, 1993), 124-130.

${ }^{32 "}$ ¡Oh Shu-sin mío que me has favorecido, 
herida infecciosa en el pie. Shu-sin reinó por nueve años. Ambos fueron deificados como dioses, y se construyeron templos para adorarlos. Su sucesor fue Ibbi-sin.

Ibbi-sin heredó de su padre un imperio gigantesco, con millares de personas para alimentar, templos para mantener, una casta sacerdotal numerosa para satisfacer y una máquina burocrática gubernamental para administrar. Aparentemente, no estaba preparado para esto o no tenía la capacidad ni el genio de sus antecesores. Ibbi-sin tenía una pobre estrategia militar como también una mala administración comercial. A pesar de todo esto tenía la obligación de mantener la unidad del imperio.

Los amorreos, al saber de la muerte de Shu-sin, empezaron a invadir el imperio rompiendo la muralla que Shulgi había construido y tomaron el control del norte. Ur y el sur ya no conseguían alimentar a una población enorme y el hambre fue la peor catástrofe que el sur debió enfrentar juntamente con la rebelión de varias ciudades estado contra la corona real. Los precios subieron de forma aterradora, la inflación se volvió alarmante y el comercio internacional se detuvo. Desesperado, Ibbi-sin pidió socorro a su general del norte Ishbi-irra, de la ciudad de Mari y de la dinastía de Isin, éste no era sumerio. Ishbi-irra lo ayudó a preservar su reino por un tiempo más, pero a un precio muy alto. Ishbi-irra tomó para si todos los estados del norte que los amorreos habían invadido. Nippur, la ciudad sagrada, pasó a ser de Ishbi-irra. Las ciudades del centro

Oh amado mío de Enlil, [mi] Shu-sin,

Oh rey mío el dios de este país!", ANET 496. 
y sur, con excepción de Ur, se rebelaron contra Ibbi-sin y dejaron de pagar tributo, a la vez que deificaron sus propios gobernantes y fortificaron las murallas de sus ciudades. Elam atacó y Ur, sin poder defenderse, cayó presa de sus enemigos. Cuando Ur cayó en las manos de los elamitas Ishbi-irra inmediatamente vino con su ejército y expulsó a los elamitas convirtiendo a Ur en su capital. Ibbi-sin terminó su vida en el exilio en Elam maldito por los dioses sumerios. Ishbi-irra inauguró su dinastía que duró cerca de cien años. La anarquía fue reemplazada por la paz y el orden gracias a este rey. Lippit-Ishtar fue el último de los reyes de esta dinastía. Los descendientes de los amorreos fundaron una dinastía en Lagash compitiendo con Lipit-Ishtar. Naplanum era el gobernador de Lagash. Trabajaba para los reyes de Isin. Sus descendientes establecieron una dinastía en Larsa y en Ur. Gungunum fue el primero de la dinastía en Larsa (1932-1906 AC). Ambos tenían algo en común, debían proteger las fuentes de agua potable y la ruta de comercio que llevaba al Golfo Pérsico. Gungunum y Lipit-Ishtar nunca lucharon en batalla; siempre resolvieron sus diferencias por medio de la diplomacia. Pero sus hijos no mantuvieron el mismo criterio. Abi-sare hijo de Gungunum entró en guerra frecuentemente con Ur-ninurta hijo de Lipit-Ishtar. Por lo tanto, estos dos reyes inauguraron un siglo de inestabilidad en el ACO. Esta anarquía causó que los canales de irrigación de los ríos se llenen de escombros y arena, bloqueando la eliminación del agua y como consecuencia la salinización de la tierra lo que provocó a su vez una baja producción de alimentos en el creciente fértil. Con la falta de alimento, aparecieron el hambre y las rebeliones en varios lugares, causando anarquía y 
guerras y como resultado hubo una declinación en la adoración al rey como deidad.

Ésta fue la oportunidad de Ilush-uma rey de Asiria. Restauró el orden y la paz en Mesopotamia, estableció su dinastía y puso fin a las invasiones nómades. Inauguró una nueva era comercial para Asur. Después de varios reyes, Shamshi-adad I (1815-1782) de Asiria, operando desde la ciudad de Terqa, unió el norte de Mesopotamia en tanto que el sur sufrió por la anarquía y la fragmentación. Su fama creció a tal punto que sólo fue eclipsado por uno de sus sucesores, Hammurabi. ${ }^{33}$

Hammurabi fue el sexto de los reyes de una larga y pacífica dinastía desde 1844 AC; después de él hubo cinco reyes más de su familia. Su logro más destacado es su código de leyes con alrededor de 280 leyes casuísticas. Hammurabi unificó Mesopotamia con los mismos límites que había tenido con Sargón. Sus hechos están relatados en los anales de Mari. Las condiciones que favorecieron a este rey fueron las siguientes: (a) una pacífica sucesión de reyes; (b) las otras naciones se encontraban con muchos problemas internos y externos para interferir con el Crecente Fértil, y (c) la genialidad de Hammurabi. Este rey se describe a sí mismo casi como un dios en la introducción de sus leyes. Se coloca a sí mismo como el defensor y protector de los débiles e indefensos, como el mediador entre los hombres y los dioses, como la luz de la tierra. ${ }^{34}$

He aquí parte del prólogo de su código:

Cuando el exaltado Anum, rey de Anunnaki, y Enlil,

${ }^{33}$ ANET, 269-270.

${ }^{34}$ Hallo y Simpson, 97. 
señor de los cielos y de la tierra, quien decreta el destino de los territorios, decretaron para Marduk, hijo primogénito de Enki, el papel de Enlil sobre toda la población, haciéndolo el más grande de los dioses Igigi, llamaron a Babilonia por su nombre, por su nombre exaltado, la hicieron preeminente en el mundo y establecieron en el mundo el reinado que tiene su fundación como el cielo y la tierra.

En este tiempo, Aum y Enlil, me llamaron por mi nombre, Hammurabi, el príncipe atento, que reverencia los dioses, que hace aparecer justicia en la tierra, para mejorar la vida y las condiciones de los pueblos, para destruir a los criminales y la maldad, para parar la opresión del fuerte sobre el débil, para levantarse como Shamash [dios sol de la justicia] sobre la humanidad e iluminar la tierra. ${ }^{35}$

\section{Conclusión}

La dinastía de Hammurabi constituye un límite histórico aceptable al que se puede llegar para obtener una clara visión del origen del culto al monarca en el ACO que continuará influyendo sobre los reyes sucesivos. Se puede concluir que las características observadas en las dinastías del ACO que propiciaron este fenómeno son las siguientes: (a) la necesidad política de tener el apoyo del clero especialmente de Nippur, el centro religioso; (b) los sacerdotes eran la voz de los dioses, por lo tanto, el pueblo aceptaba más fácilmente a aquel a quienes ellos legitimaban como rey; (c) la religión surgió primero que la monarquía y las dinastías, por lo tanto, al inicio tenía más influencia sobre sus seguidores; (d) los reyes eran los principales sostenedores de la casta

${ }^{35}$ Postgate, 268. 
sacerdotal y del templo; (e) los reyes tenían funciones similares a los dioses, pues los dioses de Sumeria eran antropomórficos en sus caracteres: tanto los dioses como los reyes mantenían el orden y el comercio, protegían a la nación contra invasores, mantenían los canales de irrigación limpios, escribían las leyes y las ejecutaban a favor del pueblo (lo que muchas veces era pura demagogia); (f) la literatura mitológica de la época mantenía estas supersticiones; (g) la cosmovisión religiosa hacía que el estado/gobierno terrestre fuese una copia del celestial; (h) la propia religión con sus tres fases de desarrollo, la de la fuerza natural de vida, la teriomórfica y la antropomórfica; finalmente (i) la conveniencia político religiosa.

Se podrían realizar otros estudios que comparen el culto a los reyes de Sumeria con los de las civilizaciones de Egipto, Roma imperial, los aztecas, los mayas, la cultura Lima, la cultura Wari (Huari), los incas, etc. Con esta nota histórica se pudo presentar apenas una clarificación de este fenómeno religioso en su estado embrionario. Por lo tanto, este asunto merece un estudio más profundo, que analice sus efectos sobre la historia de la humanidad. 